\section{Who are you Calling Old? \\ Practice Patterns and Management of \\ Nonagenarians Presenting to a Gynecologic \\ Oncologist}

Erika Ryan, MD1; Benjamin Margolis, MD1; Bhavana Pothuri, MD1

${ }^{1}$ New York University Langone Health
Gynecologic Oncology Division

Department of Obstetrics/Gynecology

\section{INTRODUCTION}

- In 2015, in patients age 85 and older, there were 1,960 cases of endometrial cancer, as well as 1,639 cases of ovarian cancer.'

- There is scant data to guide treatment decisionmaking based on tolerability, comorbidities and impact on quality of life for women aged 90 and older who are diagnosed with cancer."

\section{PURPOSE}

- To describe the practice patterns, management and overall outcomes of nonagenarians who initiated care with a gynecologic oncologist.

\section{METHOD}

- Study Type: Retrospective chart review

- Population: Female nonagenarians (age 90 and older) who consulted a gynecologic oncologist between 10/09 and 12/18 at an urban academic medical center.

- Descriptive statistics used for variables of interest.

\section{RESULTS}

- 34 nonagenarians identified (median age 92, range 90-98).

- $10(29 \%)$ had benign disease. 8 (24\%) had premalignant or suspected malignant disease, of which 5 did not pursue further workup. 16 (47\%) had malignant disease, including one who was lost to follow-up after initial consultation.

- Histologically, $44 \%$ of women had squamous subtype, $25 \%$ endometrioid, $6 \%$ clear cell, $6 \%$ poorly differentiated, and $19 \%$ adenocarcinoma.

- $79 \%$ of the time, physicians commented on age and functional status in the assessment and plan.

\section{DIAGNOSIS}

Malignant $47 \%$

Suspected malignant

Pre-malignant

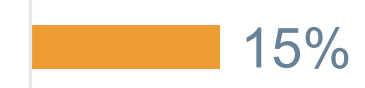

Benign $29 \%$

\section{RESULTS CONTINUED}

- Of the 15 women with cancer, $47 \%$ pursued palliative-directed treatment and $53 \%$ curative-directed treatment.

- In the curative intent group, 6 of 8 underwent surgery alone, 1 surgery and chemotherapy, and 1 chemoradiation.

- In the palliative intent group, 4 of 7 underwent radiation, 1 chemotherapy and 2 declined or unknown (lost to follow-up).

- Overall, 87\% (13 of 15) completed the proposed treatment.

- Treatment-related complications included 1 superficial skin infection and 1 thirty-day readmission for an unrelated traumatic injury.

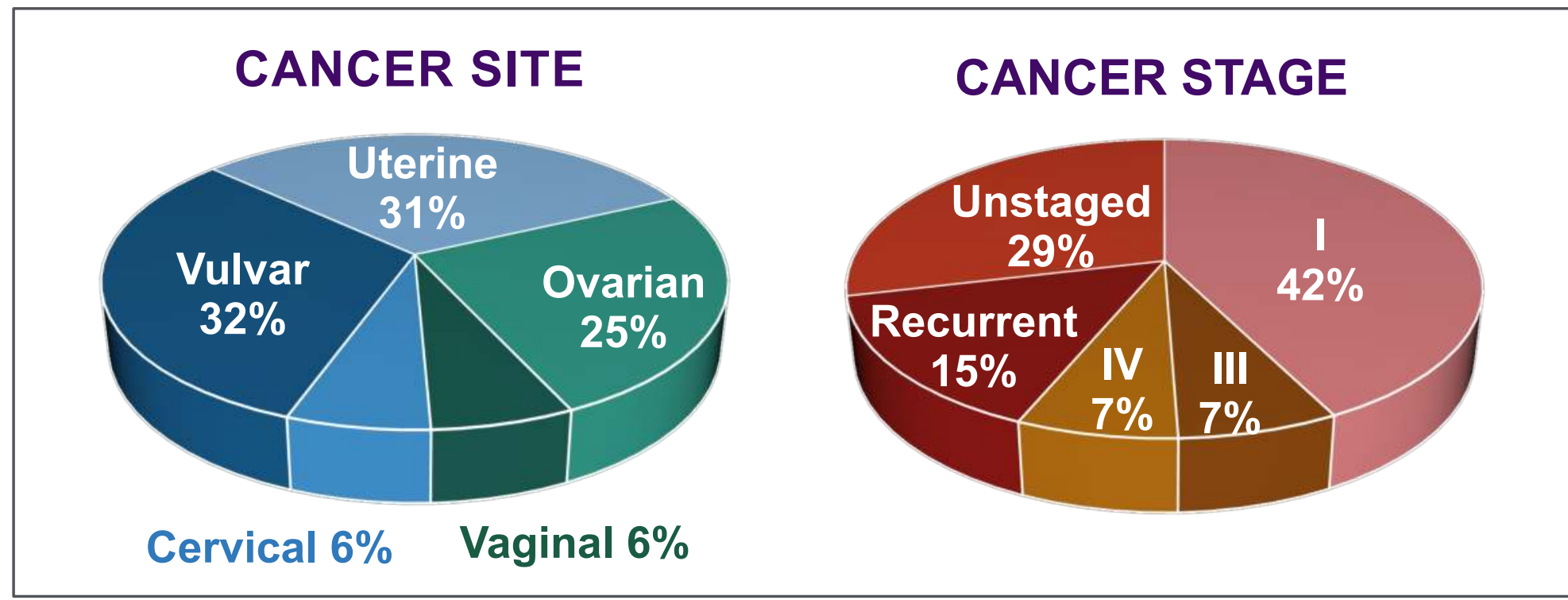

\begin{tabular}{|c|c|c|c|c|c|c|}
\hline Treatment Properties & Vulva & Vagina & Ovary & Cervix & Uterus & Total $(\%)$ \\
\hline \multicolumn{7}{|l|}{ Goal of Treatment $(n=15)$} \\
\hline Palliative & 3 & - & 2 & 1 & 1 & $7(47 \%)$ \\
\hline Curative & 2 & 1 & 2 & - & 3 & $8(53 \%)$ \\
\hline \multicolumn{7}{|l|}{ Treatment Proposed $(n=15)$} \\
\hline Radiation & 3 & - & - & 1 & 1 & $5(33 \%)$ \\
\hline Chemo & - & - & 2 & - & - & $2(13 \%)$ \\
\hline Surgery & 1 & 1 & 2 & - & 3 & $7(46 \%)$ \\
\hline Chemoradiation & 1 & - & - & - & - & $1(7 \%)$ \\
\hline \multicolumn{7}{|c|}{ Treatment Completed $(n=15)$} \\
\hline Radiation & 2 & - & - & 1 & 1 & $4(27 \%)$ \\
\hline Chemo & - & - & 1 & - & - & $1(7 \%)$ \\
\hline Surgery & 1 & 1 & 1 & - & 3 & $6(40 \%)$ \\
\hline Chemoradiation & 1 & - & - & - & - & $1(7 \%)$ \\
\hline Surgery/Chemo & - & - & 1 & - & - & $1(7 \%)$ \\
\hline Unknown & 1 & - & 1 & - & - & $2(13 \%)$ \\
\hline
\end{tabular}

\section{CONCLUSIONS}

- Nonagenarians most commonly presented with vulvar or endometrial cancer to a gynecologic oncologist.

- Of those with cancer, $87 \%$ successfully completed treatment with minimal adverse effects or toxicity.

- Age and/or functional status were addressed in the care plan for $79 \%$ of women, but did not preclude treatments that had the potential to preserve meaningful quality of life and/or cure patients of their disease. 